\title{
A Geographic Perspective on Opioid Misuse: Substance Abuse Treatment Deserts in Southwestern Ohio
}

\author{
Linnea Lowe ${ }^{1}$; Cole Brokamp ${ }^{2,3}$; Erika Rasnick ${ }^{3}$; Eric S. Hall ${ }^{4}$; Shauna Acquavita ${ }^{1,5}$
}

${ }^{1}$ School of Social Work, University of Cincinnati, Cincinnati, $\mathrm{OH}$

${ }^{2}$ College of Medicine, University of Cincinnati, Cincinnati, $\mathrm{OH}$

${ }^{3}$ Cincinnati Children's Hospital Medical Center, Cincinnati, $\mathrm{OH}$

${ }^{4}$ Geisinger, Danville, PA

${ }^{5}$ Center for Addiction Research, University of Cincinnati, Cincinnati, $\mathrm{OH}$

Corresponding Author: Linnea Lowe, School of Social Work, University of Cincinnati, PO Box 670108, Cincinnati, OH 45267-0108, lowela@mail.uc.edu Submitted November 22, 2020 Accepted April 6, 2021 Published June 21, 2021 https://doi.org/10.18061/ojph.v4i1.8075

\section{ABSTRACT}

Background: The opioid crisis is one of the most pressing public health issues facing Ohio, with an impact unevenly distributed across the state. This work examined geographical barriers to substance abuse treatment in southwestern Ohio through examining geographical areas with limited access to substance abuse treatment services and identifying substance abuse treatment deserts.

Methods: The study domain included the 13 counties in the Ohio Mental Health and Addiction Service's Cincinnati region. Publicly available substance use disorders treatment data were collected from government agency resources, pharmaceutical websites, and web searches. Substance abuse treatment deserts were defined as areas in the 13-county study area that were not within a 15-minute drive from a treatment center.

Results: We found large portions of the study region that were considered a substance abuse treatment desert for methadone and naltrexone/buprenorphine clinics, behavioral health treatment centers, and both medicated assisted treatment (MAT) and behavioral health treatment combined. Out of the 2017337 total persons living in the 13-county study area, $17 \%(n=342872)$ live in a desert for all MAT and behavioral treatment. Similarly, $19.7 \%(n=396581)$ live in a desert for naltrexone/buprenorphine treatment, $60.9 \%(n=1227560)$ live in a desert for methadone treatment, and $19.7 \%(n=396581)$ live in a desert for behavioral health treatment.

Conclusion: We successfully defined substance abuse treatment deserts in southwestern Ohio, which will be useful for future research to determine its association with opioid-related health outcomes. This resource is publicly available online (https://doi.org/10.5281/zenodo.4011051).

Keywords: Opioid abuse; Treatment desert; Medicated assisted treatment; Behavioral health treatment; Geospatial

\section{INTRODUCTION}

In recent decades, an opioid epidemic has gripped the United States resulting in an unprecedented public health crisis. ${ }^{1}$ Between 1999 and 2019, the number of opioid-involved overdose deaths increased almost 6 -fold, with opioids involved in nearly $70 \%$ of the over 67000 overdose deaths in 2019.2,3 That same year, an estimated 2 million people were diagnosed with an opioid use disorder; of those, only about $20 \%$ received substance use treatment in the previous year. ${ }^{3}$ The necessity of access and availability to specialty drug treatments for opioid dependence is highlighted by studies that have demonstrated that these types of treatments 
reduce the risk of overdose mortality. ${ }^{4}$ While affordability of treatment increased in recent years for many low-income individuals due to Medicaid expansion under the Patient Protection and Affordable Care Act of 2010,5 geographic accessibility continues to be an area of concern. Cummings and colleagues ${ }^{6}$ found that while approximately $60 \%$ of counties in the United States have at least 1 outpatient substance abuse treatment facility that accepts Medicaid, this rate was lower in many southern and midwestern states. Furthermore, counties with a higher percentage of Black, rural, and/or uninsured residents were less likely to have a facility that accepted Medicaid. Other studies suggest that primary care providers who practice in rural areas and/or communities with larger Black and Latinx populations have fewer, geographically, behavioral health professionals providing mental health and substance use services. ${ }^{7}$

Ohio has been hit especially hard by the epidemic, with opioid overdoses resulting in over 500000 total years of lost life from 2010 to $2016 . .^{8}$ In 2007, unintentional drug poisoning became the leading cause of injury death in Ohio and, unfortunately, this remains true as of this writing. As an epicenter of the crisis, the opioid mortality rate doubled every 3 years from 1999 to $2016 .{ }^{9}$ As in much of the country, there has been an uneven distribution of opioid overdose mortality throughout Ohio. A geospatial analysis using data from 2010 through 2017 found that the increasing rates of the opioid overdose epidemic in Ohio were driven by 12 epidemic hotspot areas, 5 of which are part of the Greater Cincinnati area. ${ }^{10}$ Of these, 3 were in the Appalachian Region, a cultural, social, and economic region that spans the Appalachian Mountains. ${ }^{11}$ Rural Appalachian counties have the highest mortality rates in the region with $65 \%$ higher overdose mortality compared to nonAppalachian counties. ${ }^{12}$

The concept of deserts to describe geographical areas with limited access to goods and services has been used in popular discourse in recent decades. The term food desert was initially used to describe geographic areas where people experienced physical and economic barriers to accessing healthy food.13 Older studies utilized the former Food Desert Atlas from the United States Department of Agriculture Economic Research Service, which provided a food desert measure for each census tract. A census tract was classified as low access if at least 500 residents, or $33 \%$ of the tract population, lived over 10 miles from a supermarket, based on Euclidean distance. ${ }^{14}$ In more recent literature, the term food desert is used to imply the inability to easily acquire food with high nutritional content, rather than a lack of access to food per se.15,16 This has led researchers to consider other factors that could impact food desert status. Potential factors include explicit and implicit travel costs for consumers in addition to food costs ${ }^{15}$ and perceptions of the acceptability of food stores and shopping locations. ${ }^{17}$

The term health care desert has also been applied to areas where residents of an area or region must travel significant distances to obtain health care services. ${ }^{18}$ Specifically, areas where disparities in access to pharmacy, hospital, trauma, and medical services exist have been identified as deserts.19-21 Additionally, treatment deserts have been used to conceptualize restricted access to treatment in rural areas. A scoping review of opioid misuse in rural America found a theme of treatment deserts in 2 key areas: 1) areas where a small proportion of primary care physicians received buprenorphine waivers and 2) areas where treatment facility types were further for Appalachian versus non-Appalachian and rural versus micropolitan/metropolitan patients. ${ }^{21}$

These examinations of food and health care deserts have been modes through which to identify and explore barriers to goods and services, vital to the health and well-being of vulnerable individuals and communities. Applying a similar paradigm as the original use of the term food desert, this project examined geographical barriers to substance abuse treatment in a greater Cincinnati, Ohio, region, and explored the existence of substance abuse treatment deserts, as defined by individuals living more than a 15minute drive from a treatment center.

\section{METHODS}

\section{Setting and Design}

Included counties were part of the Ohio Department of Mental Health and Addiction Services (OMHAS) Cincinnati region: Adams, Butler, Brown, Clermont, Clinton, Fayette, Hamilton, Highland, Lawrence, Pike, Ross, Scioto, and Warren. ${ }^{22}$ See Figure 1.

\section{Procedures}

Publicly available substance abuse treatment data were obtained from the Substance Abuse Mental Health Services Administration (SAMHSA) website (https://findtreatment.samhsa.gov/), the OMHAS Emerald Jenny Treatment Finder tool (https:// www.emeraldjennyfoundation.org), the Commission on Accreditation of Rehabilitation Facilities (CARF) website (http:// www.carf.org/providerSearch.aspx), the Ohio Behavioral Health Directory (https://prod.ada.ohio.gov/directory/), and the Find a Treatment Provider tool on the Vivitrol website (https:// www.vivitrol.com/find-a-treatment-provider) between August 2019 and February 2020. Additional facilities were found by using Google (www.google.com) to search substance+abuse+treatment and the respective county. Discrepancies between websites for contact information and services were reconciled by calling the facility to confirm the correct address and available services.

\section{Measures/Outcomes}

The street addresses of treatment facilities were geocoded using a standalone, validated geocoder based on Census TIGER/Line street range address files. ${ }^{23,24}$ A geocode is considered accurate if coordinates are placed on the correct street or within the correct street segment, and the input address text and resulting geocoded address text are at least a 50\% match. The current study excluded treatment facilities that could not be accurately geocoded. Out of 260 treatment centers, 250 were able to be accurately geocoded. 


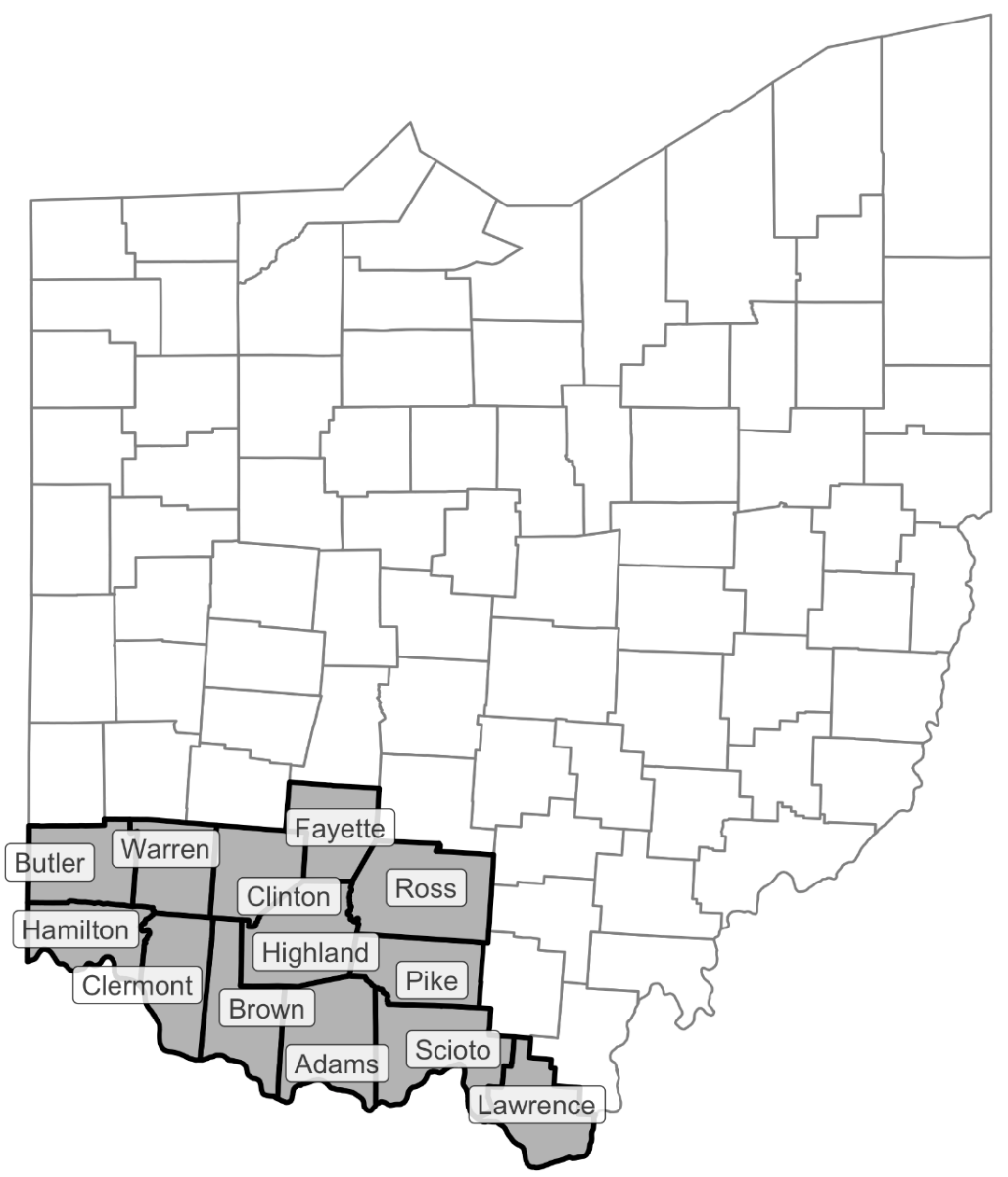

Figure 1. Map of the Study Regions, the OMHAS Cincinnati Region

Polygons consisting of 15-minute drive times from each treatment center were generated using the openroute service API. ${ }^{25}$ We defined 4 types of deserts based on the 3 treatment types and access to any of the treatment types (naltrexone/buprenorphine, methadone, behavioral, and overall). The union of these individual access polygons for each treatment facility was used to define areas of treatment access for each desert type. Substance abuse treatment deserts were defined as areas in the 13-county study area not covered by the treatment access areas. To estimate the number and percentage of people living in substance abuse treatment desert areas, population estimates for the 13-county study area were obtained from the 2010 US Census at the census block level. Each census block was classified as a substance abuse treatment desert if it overlapped with the defined desert area. Geospatial and statistical computing was done using $\mathrm{R}$, version 3.6.3. ${ }^{26}$ Specifically, we used the sf package for all geospatial calculations. ${ }^{27}$

\section{RESULTS}

Figure 2 shows maps of the 13-county study area with substance abuse treatment desert regions highlighted in colors for each respective treatment type. The upper left map panel combines deserts for all substance abuse pharmacological and behavioral treatment deserts, meaning that these areas lack access to all 3 types of treatments.

Overall, out of the 2017337 total persons living in the 13-county study area, $17 \%(n=342872)$ live in a desert for all MAT and outpatient behavioral treatment. Similarly, 19.7\% $(n=396581)$ live in a desert for naltrexone/buprenorphine treatment, $60.9 \%$ $(n=1227560)$ live in a desert for methadone treatment, and $19.7 \%(n=396581)$ live in a desert for behavioral treatment. When considering the fraction of population living in a substance abuse treatment desert by county, the percentages ranged from $5 \%$ to $57 \%$. Table 1 presents the population and percentage of total population living in a substance abuse treatment desert for each county in the study region. The table presents the data substance abuse treatment desert percentage for all counties in the study region. For the 13-county study area region, the largest desert centered on methadone (61\%), with many counties not having access to any methadone treatment. Naltrexone/buprenorphine followed (20\%), and outpatient behavioral treatment was next (18\%).

The counties fell into 2 subregions. The first is a 3-county subregion where the substance abuse treatment desert was $7 \%$ or less 
All MAT and Behavioral

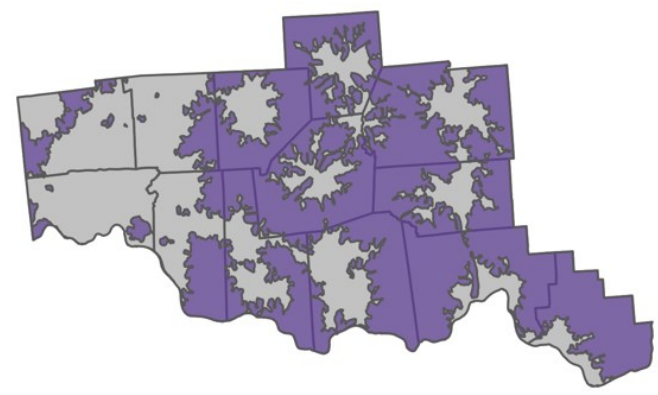

Methadone

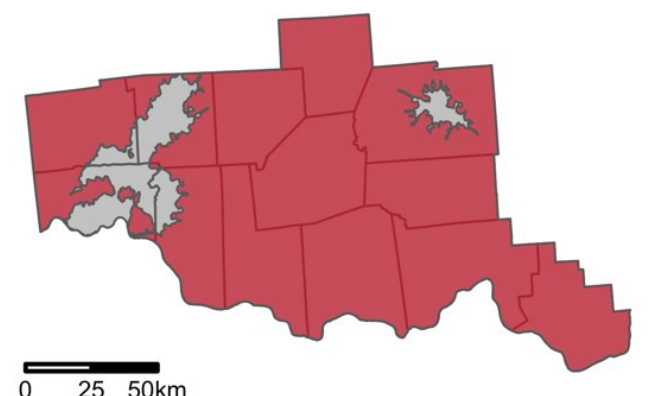

Naltrexone/Buprenorphine

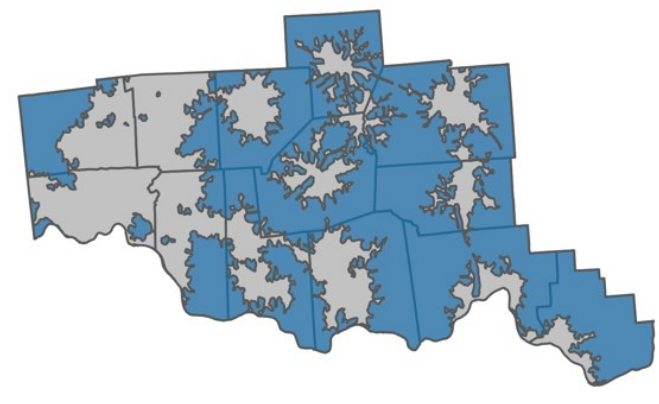

Behavioral

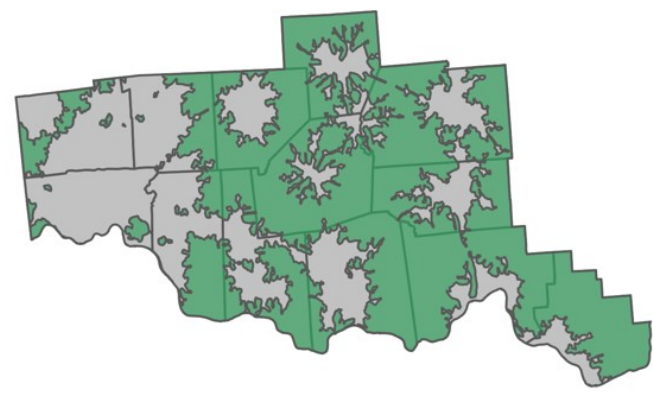

Figure 2. Maps of the 13-County Study Region with Substance Abuse Treatment Deserts Highlighted in Color for Each Type of Treatment

of the individual county's population, indicating a greater availability for substance use disorder treatment (5\% to $7 \%$ ). The second is a 10-county region where the substance abuse treatment desert was greater than $22 \%$ of the individual county's population (22\% to $57 \%$ ), indicating a dearth of treatment.

\section{DISCUSSION}

In this project, we identified substance abuse treatment deserts in a 13-county region in southwestern Ohio. Substance abuse treatment deserts were defined as areas that were not within a 15minute drive from a treatment center, including methadone and naltrexone/buprenorphine clinics, behavioral health treatment centers, and both medicated assisted treatment (MAT) and behavioral health treatment combined.

Further examination of subregional differences in the identified regions looked at differences in Appalachian status, overdose mortality rates, opioid dispensing rates, and poverty rates. Although no counties within the first subregion overlapped with the Appalachian region, 8 of the 10 counties in subregion 2 were part of the Appalachian region. This second subregion also contained the largest substance abuse treatment desert area. In the substance abuse treatment desert subregion where treatment was more available, the average opioid dispensing rate per 100 residents was lower (51.6\% versus $70.9 \%)$, as was the poverty rate $(11.7 \%$ versus
18.6\%). ${ }^{28,29}$ While differences in the poverty and opioid dispensing rates were found between the 2 regions, delineation between the 2 regions in terms of accidental drug overdose rates is unclear. This may be related to specific classes of opioid mortality on the county level. Monnat and colleagues found that while drug mortality rates overall were higher in counties with higher economic disadvantage and opioid dispensing rates, counties with higher heroin mortality and very high and rapidly growing mortality rates from all types of opioids were more urban and less economically disadvantaged. ${ }^{30}$

Butler and Hamilton counties were categorized into the first subregion. While residents had more access to treatment, the number and age-adjusted accidental drug overdose rates for 2013 through 2018 had ranges corresponding with regions that have a dearth of treatment. ${ }^{31}$ Butler and Hamilton counties are more urban with the first and second highest proportion of urban population in the study region. ${ }^{32}$ These counties also had the second and fourth lowest poverty rates of the study region. ${ }^{29}$ Monnat and colleagues classified these counties as 2 with a very high and rapidly growing mortality rate from all types of opioids with data from 2014 to $2016 .{ }^{30}$ This aligns with their conclusion that higher overdose rates cannot be fully explained by the rate of opioid prescriptions dispensed and availability of substance abuse treatment. ${ }^{30}$ 
The third county in the first subregion, Warren County, had the lowest overdose mortality rate of any of the counties in the study region, the lowest dispensing rate, and the lowest poverty rate. ${ }^{28,29,31}$ The data from this county and the other subregion, aside from 1 outlier county, coincided with the main finding of Monnat and colleagues, ${ }^{30}$ that overall mortality rates were lower in those counties with less economic disadvantage and lower opioid dispensing rates.

The outlier in the second subregion, Highland County, had the largest substance abuse treatment desert, the highest opioid dispensing rate, and a poverty rate comparable to the other counties, yet the number and age-adjusted accidental drug overdose rate for 2013 to 2018 was 23.6, the 48th highest rating in the state. ${ }^{31}$ The other 9 counties in the second group ( 7 of which enclose Highland County) had ratings ranging from 2nd to 19th. Despite the lower accidental drug overdose rate, substance abuse is still a significant concern in Highland County. Not only was illegal drug use listed as the number one health issue by the general public and health professionals in 2016,33 but the Centers for Disease Control and Prevention has identified Highland County as 1 of 220 counties in the United States particularly vulnerable for significant increases in HIV and hepatitis $\mathrm{C}$ infections due to injection drug use. ${ }^{34} \mathrm{~A}$ further examination of this county is warranted to identify how other county-level protective factors could be mobilized by communities when medical and behavioral health substance abuse interventions are more limited. A case study may find that factors such as social capital ${ }^{35}$ or local initiatives, such as the implementation of the Byrne Criminal Justice Innovation program, ${ }^{36}$ may be driving forces in preventing overdose deaths.

A strength of our analysis was that we utilized driving time, rather than "as the crow flies" distance to define proximity to treatment facilities. Currently, there is little evidence on the impact of total travel time for treatment adherence among substance use disorder patients. We chose 15 minutes as our threshold for the accessibility of treatment because regular access to treatment is more similar to regular access to health food retailers (which usually use 15 minutes) rather than to acute care (which usually use 60 minutes), which is required much less often and regularly. Regardless, the threshold of accessibility as a driving time likely differs among patients based on their personal behaviors and beliefs, as well as on how much they usually travel daily, their access to a vehicle, and whether or not they live in a rural or urban area.

A limitation of this project is that we only considered transportation by car, which misrepresents patients that may lack access to a car. Patients that walk or utilize public transportation systems, such as a bus, are not represented in our calculation of these treatment deserts. Future work should extend the definition of treatment deserts to include travel time related to other modes of transportation. Our existing treatment deserts could be combined

Table 1. Population (and percent of total population) Living in Substance Abuse Treatment Deserts Overall and by County in the Study Region

\begin{tabular}{|c|c|c|c|c|}
\hline County & All & Naltrexone/Buprenorphine & Methadone & Outpatient behavioral \\
\hline Entire study region & 342872 (17\%) & 396581 (20\%) & 1227560 (61\%) & 360275 (18\%) \\
\hline \multicolumn{5}{|l|}{ Subregion 1} \\
\hline Butler & $17281(5 \%)$ & 53145 (14\%) & $303086(82 \%)$ & $17281(5 \%)$ \\
\hline Hamilton & $50060(6 \%)$ & $58814(7 \%)$ & 299016 (37\%) & $50060(6 \%)$ \\
\hline Warren & $14994(7 \%)$ & $15019(7 \%)$ & $112501(53 \%)$ & $28076(13 \%)$ \\
\hline \multicolumn{5}{|l|}{ Subregion 2} \\
\hline Clermont & $43018(22 \%)$ & $43018(22 \%)$ & $111454(56 \%)$ & $43018(22 \%)$ \\
\hline Fayette & $9792(34 \%)$ & 10895 (38\%) & 29030 (100\%) & $10120(35 \%)$ \\
\hline Ross & 34170 (44\%) & $36158(46 \%)$ & 42790 (55\%) & 34170 (44\%) \\
\hline Scioto & 36426 (46\%) & 36937 (46\%) & 79499 (100\%) & $36426(46 \%)$ \\
\hline Adams & 14008 (49\%) & 14008 (49\%) & 28550 (100\%) & $14008(49 \%)$ \\
\hline Clinton & 22600 (54\%) & 22600 (54\%) & 42040 (100\%) & $22611(54 \%)$ \\
\hline Brown & $24576(55 \%)$ & $24576(55 \%)$ & 44846 (100\%) & 24576 (55\%) \\
\hline Lawrence & 35060 (56\%) & 38708 (62\%) & $62450(100 \%)$ & 35060 (56\%) \\
\hline Pike & $16050(56 \%)$ & 17866 (62\%) & 28709 (100\%) & 16050 (56\%) \\
\hline Highland & 24837 (57\%) & 24837 (57\%) & 43589 (100\%) & 28819 (66\%) \\
\hline
\end{tabular}

Percentages were calculated as the fraction of the total population. 
with census survey data on the number of vehicles per household to estimate where this limitation would be the greatest.

\section{PUBLIC HEALTH IMPLICATIONS}

The geographically-defined regions identified in this study could be useful to study their impact on substance use disorder diagnosis and treatment outcomes. The geographically-defined substance abuse treatment desert locations are available to the public online as GeoPackage data files (https://doi.org/10.5281/ zenodo.4011051). Approximately 1 in 6 of the individuals residing within the study area lived more than a 15-minute drive from any type of MAT or behavioral treatment facility. Consistent with findings of other researchers, ${ }^{37}$ we found treatment deserts disproportionally distributed across rural communities. Furthermore, if there are substance abuse treatment centers in rural areas, those living in rural communities face transportation barriers due to distance and limited public transportation options. ${ }^{38}$ These transportation and distance barriers may contribute to inadequate substance abuse treatment or relapse. As has been proposed, offering MAT through primary care providers or expanding transportation services through substance abuse treatment programs are potential ways to improve access and utilization for those living in substance abuse treatment deserts. ${ }^{39,40}$

\section{ACKNOWLEDGMENTS}

Acknowledgements and Funding: There is no funding to declare.

\section{REFERENCES}

1. Kaufman R, Durkin, K. Impact of emotional distress on prescription opioid abuse in a rural juvenile drug court sample. Ohio J Public Health. 2019;2:37-43. Accessed September 8, 2020. https://ohiopha.org/wp-content/uploads/2020/04/7-0JPH-2019-201 -Kauffman-FINAL-11-01-19.pdf

2. Centers for Disease Control and Prevention. Opioid data analysis and resources. Accessed February 19, 2021. https://www.cdc.gov/drugoverdose/data/analysis.html

3. Substance Abuse and Mental Health Services Administration. Key substance use and mental health indicators in the United States: Results from the 2018 national survey on drug use and health. 2019; No. PEP19-5068, NSDUH Series H-54. Rockville, MD: Center for Behavioral Health Statistics and Quality, Substance Abuse and Mental Health Services Administration.

4. Davoli M, Bargagli AM, Perucci CA, et al. Risk of fatal overdose during and after specialist drug treatment: the VEdeTTE study, a national multi-site prospective cohort study. Addiction. 2007;102(12):19541959.

https://doi.org/10.1111/j.1360-0443.2007.02025.x

5. Wen H, Hockenberry JM, Borders TF, Druss BG. Impact of Medicaid expansion on Medicaid-covered utilization of buprenorphine for opioid use disorder treatment. Med Care. 2017;55(4):336-341. https://doi.org/10.1097/MLR.0000000000000703

6. Cummings JR, Wen H, Ko M, Druss BG. Race/ethnicity and geographic access to Medicaid substance use disorder treatment facilities in the United States. JAMA Psychiatry. 2014;71(2):190-196 https://doi.org/10.1001/jamapsychiatry.2013.3575
7. Wielen LM, Gilchrist EC, Nowels MA, Petterson SM, Rust G, Miller BF. Not Near Enough: Racial and Ethnic Disparities in Access to Nearby Behavioral Health Care and Primary Care. J Health Care Poor Underserved. 2015;26(3):1032-1047. https://doi.org/10.1353/hpu.2015.0083

8. Hall OT, Hall OE, McGrath RP, Haile ZT. Years of life lost due to opioid overdose in Ohio: Temporal and geographic patterns of excess mortality. J Addict Med. 2020;14(2) https://doi.org/10.1097/ADM.0000000000000554

9. Kiang MV, Basu S, Chen J, Alexander MJ. Assessment of changes in the geographical distribution of opioid-related mortality across the United States by opioid type, 1999-2016. JAMA Netw Open. 2019;2

(2):e190040

https://doi.org/10.1001/jamanetworkopen.2019.0040

10. Hernandez A, Branscum AJ, Li J, MacKinnon NJ, Hincapie AL, Cuadros DF. Epidemiological and geospatial profile of the prescription opioid crisis in Ohio, United States. Sci Rep. 2020;10(1):4341-10. https://doi.org/10.1038/s41598-020-61281-y

11. Pollard KM. A "New Diversity": Race and Ethnicity in the Appalachian region. Washington DC: Appalachian Regional Commission and Population Reference Bureau; 2004.

12. Meit M, Heffernan M, Tanenbaum E. Investigating the impact of the diseases of despair in Appalachia. J Appalach Health. 2019;1(2):7-18. https://doi.org/10.13023/jah.0102.02

13. Reisig V, Hobbiss A. Food deserts and how to tackle them: a study of one city's approach. Health Educ J. 2000;59(2):137-149. https://doi.org/10.1177/001789690005900203

14. Ver Ploeg, M., Dutko, P., Breneman, V. (2014;2015;). Measuring food access and food deserts for policy purposes. Appl Econ Perspect Policy. $37(2): 205-225$ https://doi.org/10.1093/aepp/ppu035

15. LeClair MS, Aksan A. Redefining the food desert: combining GIS with direct observation to measure food access. Agric Hum Values. 2014;31 (4):537-547. https://doi.org/10.1007/s10460-014-9501-y

16. Sadler RC, Gilliland JA, Arku G. Theoretical issues in the 'food desert' debate and ways forward. GeoJournal. 2016;81(3):443-455. https://doi.org/10.1007/s10708-015-9634-6

17. Sadler RC, Sanders-Jackson AN, Introne J, Adams R. A method for assessing links between objectively measured food store scores and store \& neighborhood favorability. Int J Health Geogr. 2019;18(1):31. https://doi.org/10.1186/s12942-019-0195-7

18. Sanders SR, Erickson LD, Call VRA, Rugh JS, McKnight ML. Healthcare use in the heartland: How health care selection varies between rural, retirement-Age migrants and long-term residents. Rural Sociol. 2016;81(1):66-98. https://doi.org/10.1111/ruso.12088

19. Harant P. Hospital cooperation across French Borders. In Rosenmoeller M, McKee M, Baeten R, ed. Patient Mobility in the European Union: Learning from Experience. Copenhagen, DK: WHO Regional Office for Europe; 2006:157-177. Accessed September 8, 2020. https://www.euro.who.int/_data/assets/pdf_file/0005/98420/ Patient_Mobility.pdf

20. Qato DM, Daviglus ML, Wilder J, Lee T, Qato D, Lambert B. 'Pharmacy deserts' are prevalent in Chicago's predominantly minority communities, raising medication access concerns. Health Aff. 2014;33(11):1958- 
1965.

https://doi.org/10.1377/hlthaff.2013.1397

21. Palombi LC, St Hill CA, Lipsky MS, Swanoski MT, Lutfiyya MN. A scoping review of opioid misuse in the rural United States. Ann Epidemiol. 2018;28:641-652.

https://doi.org/10.1016/j.annepidem.2018.05.008

22. Ohio Substance Abuse Monitoring (OSAM). Ohio Department of Mental Health and Addiction Services website. Access September 20, 2020.

23. Brokamp C, Wolfe C, Lingren T, Harley J, Ryan P. Decentralized and reproducible geocoding and characterization of community and environmental exposures for multisite studies. J Am Med Inform Assoc. 2018;25:309-314.

https://doi.org/10.1093/jamia/ocx128

24. Brokamp C. DeGAUSS: Decentralized Geomarker Assessment for MultiSite Studies. J Open Source Softw. 2018;3:812.

https://doi.org/10.21105/joss.00812

25. Openrouteservice. Accessed June 25, 2020. https://openrouteservice.org/

26. $\mathrm{R}$ Core Team. $R$ : A language and environment for statistical computing. R Foundation for Statistical Computing. 2020. Accessed June 25, 2020. https://www.R-project.org/

27. Pebesma E. Simple features for R: Standardized support for spatial vector data. $R J .2018 ; 10: 439-446$. https://doi.org/10.32614/RJ-2018-009

28. Centers for Disease Control and Prevention. U.S. County Opioid Dispensing Rates, 2018. Accessed on February 7, 2021. https://www.cdc.gov/drugoverdose/maps/rxcounty2018.html

29. Ohio Development Services Agency. The Ohio poverty report: February 2017. Accessed on September 20, 2020. https://www.development.ohio.gov/files/research/p7005.pdf

30. Monnat SM, Peters DJ, Berg MT, Hochstetler A. Using Census data to understand county-level differences in overall drug mortality and opioid-related mortality by opioid type. Am J Public Health (1971). 2019;109:1084-1091. https://doi.org/10.2105/AJPH.2019.305136

31. Ohio Public Health Information Warehouse. Ohio Resident Mortality Data, 2018. Accessed June 25, 2020. http://publicapps.odh.ohio.gov/EDW/DataCatalog

32. United States Census Bureau. 2010 census urban and rural classification and urban area criteria. Accessed on May 2, 2021. https://www.census.gov/programs-surveys/geography/guidance/geo -areas/urban-rural/2010-urban-rural.html

33. Highland County Community Action Organization. Highland County Community Health Report: Summary of Findings. Columbus, OH: The Ohio State University; 2016. Accessed February 18, 2021. https://comdev.osu.edu/sites/comdev/files/imce/Highland\% 20County\%20Community\%20Health\%20Report $\% 20 \% 20-\% 20$ April $\%$ 202016.pdf

34. Van Handel MM, Rose CE, Hallisey EJ, et. al. County-level vulnerability assessment for rapid dissemination of HIV or HCV infections among persons who inject drugs, United States. J Acquir Immune Defic Syndr. 2016;73(3): 323-331. https://doi.org/10.1097/QAI.0000000000001098

35. Zoorob MJ, Salemi JL. Bowling alone, dying together: The role of social capital in mitigating the drug overdose epidemic in the United
States. Drug Alcohol Depend. 2017;173:1-9.

https://doi.org/10.1016/j.drugalcdep.2016.12.011

36. Local Initiatives Support Corporation. CBCR in Action. Accessed February 18, 2021.

https://www.lisc.org/our-initiatives/safety-justice/cbcr/where-ithappening/sites/highland-county-ohio/

37. Joudrey PJ, Edelman EJ, Wang EA. Drive times to opioid treatment programs in urban and rural counties in 5 US states. JAMA. 2019;322:1310-1312. https://doi.org/10.1001/jama.2019.12562

38. Pullen E, Oser C. Barriers to substance abuse treatment in rural and urban communities: Counselor perspectives. Subst Use Misuse. 2014;49(7):891-901. https://doi.org/10.3109/10826084.2014.891615

39. Samet JH, Botticelli M, Bharel M. Methadone in primary care - one small step for Congress, one giant leap for addiction treatment. $N$ EnglJ Med. 2018;379:7-8. https://doi.org/10.1056/NEJMp1803982

40. Whetten R, Whetten K, Pence BW, Reif S, Conover C, Bouis S. Does distance affect utilization of substance abuse and mental health services in the presence of transportation services? AIDS Care. 2007;2006;18:27-34. https://doi.org/10.1080/09540120600839397 